\title{
(6) OPEN ACCESS \\ A study of Foundation Year doctors' prescribing in patients with kidney disease at a UK renal unit: a comparison with other prescribers regarding the frequency and type of errors
}

\author{
Rakesh Patel, ${ }_{1}^{1}$ William Green, ${ }^{2}$ Maria Martinez Martinez, ${ }^{3}$ \\ Muhammad Waseem Shahzad, ${ }^{4}$ Chris Larkin ${ }^{4}$
}

${ }^{1}$ Department of Medical and Social Care Education, University of Leicester, Leicester, UK

${ }^{2}$ School of Management, University of Leicester Leicester, UK

${ }^{3}$ University Hospitals of Leicester NHS Trust, Leicester, UK

${ }^{4}$ Health Education East Midlands, Leicester, UK

Correspondence to Dr Rakesh Patel, Department of Medical and Social Care Education, 107 Princess Road East, Leicester LE1 7LA, UK; rp299@le.ac.uk

Received 3 December 2014 Revised 20 February 2015 Accepted 24 February 2015 Published Online First 31 March 2015
CrossMark

To cite: Patel $R$, Green $W$, Martinez MM, et al. Eur J Hosp Pharm 2015;22: 291-297.

\section{ABSTRACT}

Objectives Errors in prescribing can cause avoidable harm to patients. Establishing the extent of prescribing errors across medical specialties is critical. This research explores the frequency and types of prescribing errors made by healthcare professionals prescribing for patients with renal disease where prescribing problem-solving and decision-making is complex due to comorbidity. Methods All prescriptions and errors made by prescribers were captured over a 4-month period in a UK renal unit. Data were recorded concerning the medicine associated with the error, the type and severity of the error, and the prescriber's occupational grade.

Results 10394 prescribed items were captured and $3.54 \%$ had associated prescribing errors. While Foundation Year 1 doctors made almost one error each week (mean 15.13) and Foundation Year 2 doctors one every 2 weeks (mean 8.00), other prescribers made one error per month (mean 3.94). The medicines most frequently associated with errors for Foundation doctors were paracetamol $(6.51 \%)$, calcium acetate $(5.33 \%)$, meropenem (3.55\%), alfacalcidol (3.55\%) and tazocin $(3.55 \%)$, while for all other prescribers they were meropenem (6.15\%), alfacalcidol (4.62\%), co-amoxiclav (4.62\%) and tacrolimus (4.62\%). The most common types of error for both groups were omitting the indication, using the brand name inappropriately, and prescribing inaccurate doses.

Conclusions The range of errors made by multiprofessional healthcare prescribers confirms the complexity of prescribing on a renal unit for patients with kidney disease and multimorbidity. These findings have implications for the types of educational interventions required for reducing avoidable harm and overcoming human factors challenges to improve prescribing behaviour.

\section{INTRODUCTION}

Patients with kidney disease across the spectrum of acute kidney injury through to chronic kidney disease (CKD) requiring renal replacement therapy are particularly vulnerable to avoidable harm from medication. ${ }^{12}$ Patients with CKD tend to be older than the general population and so have more long term conditions and multimorbidity which requires management with medication. ${ }^{3}$ As a consequence of this disease burden, patients with CKD are also likely to be prescribed several different medicines (polypharmacy). ${ }^{5}$
Increased patient multimorbidity and polypharmacy all lead to a greater risk of adverse reactions, so preventing avoidable harm from medication in this group of patients is particularly important. ${ }^{6}$ Medicine dose and dose interval adjustments are an important part of this strategy. However, calculations can be complicated and the risk of potential harm from prescribing errors remains. ${ }^{178}$ Furthermore, some of the medicines used in renal medicine and transplantation are subject to clinically significant drug and food interactions that can also result in patient harm. Consequently, patients with kidney disease are vulnerable to avoidable harm and adverse events due to complications from incorrectly prescribed medicines.

Safe prescribing is a key element of any patient safety initiative. Dean et al defined a prescribing error as "an unintentional significant (1) reduction in the probability of treatment being timely and effective or (2) increase in the risk of harm when compared with generally accepted practice" (ref. 9, p. 235). Prescribing errors are common in the workplace, with reported rates of between $7 \%$ and $15 \%{ }^{10}{ }^{11}$ Establishing the type of prescribing errors in relation to the professional group and occupational grade of the prescriber provides a more nuanced understanding of the problem. In a study of prescribing errors in hospital inpatients in the UK, Dean et al observed that junior doctors were responsible for the greatest proportion of errors. ${ }^{12}$ Dornan $e t a l^{13}$ reported that doctors in the first 2 years of qualified practice were more likely to make a prescribing error compared to other prescribers such as consultants, nurses or pharmacists. These differences in prescriber occupation warrant further attention since there is evidence that pharmacists make almost no medical errors when prescribing. ${ }^{14}$ The findings of Dornan et al ${ }^{13}$ also suggest that the prescribing behaviour of prescribers, particularly Foundation Year (FY) doctors, requires close attention, with hospital admission associated with a greater risk that patients may experience a prescribing error.

Given the potential threat to patient safety posed by inexperienced FY doctors (doctors in their first 2 years of practice following graduation from medical school in the UK), increasing the effectiveness of their prescribing is paramount. A variety of educational interventions to improve prescribing competency have been proposed. In a recent systematic review, Kamarudin et $a l^{15}$ found that most 
evidence supported the use of the WHO Guide to Good Prescribing for improving prescribing competence in medical professionals. They also reported that continuing education and personalised feedback produce positive results. ${ }^{15}$

Alongside these educational interventions, references sources such as the Renal Drug Handbook ${ }^{16}$ and the electronic Medicines Compendium ${ }^{17}$ also support FY doctors prescribing for patients with kidney disease. While these resources can be found in the workplace, it remains unclear whether making more supports available can help FY doctors prescribe safely in patients with kidney disease. FY doctors perceive renal medicine as difficult and challenging, particularly around acid-base and electrolyte disorders and dialysis. ${ }^{18}$ As a result, Jhaveri et $a l^{18}$ suggest that alternate and innovative methods of teaching renal medicine are necessary, however there are few alternatives to traditional textbooks or manuals on how to prescribe in patients with kidney disease.

Jhaveri et $a l^{18}$ found that FY doctors wanted more practical prescribing education and explicit feedback on their general prescribing performance. Consequently, the prescribing performance of individuals in each prescribing context needs to be studied. Besides informing a targeted programme of education, elucidating the type of prescribing errors and the most common medicines involved will provide guidance on how best to design and deliver education in partnership with other health professionals such as pharmacists and nurses.

The prevalence of prescribing errors has been widely reported. $^{2} 8$ 10-13 19-22 However, there is little information about the nature of the problem in specific prescribing contexts such as renal units or among patients with renal disease. Without this context specificity, knowledge of prescribing errors for informing targeted educational interventions is limited. Although the type of prescribing errors observed in a renal unit has been previously reported in a study from Iran, there is no research specifically exploring the prevalence and type of prescribing errors among FY doctors in the UK. ${ }^{22}$

The aim of this research was to explore the types of errors in relation to the medicines involved, and the type and severity of errors made by FY doctors when prescribing in patients with kidney disease. This information will provide a better understanding of the educational needs around the prescribing of FY doctors working in UK renal units compared with other healthcare professionals.

\section{METHODS}

\section{Context}

Clinical pharmacists reviewed all handwritten medicine prescriptions on inpatient medication charts over a 4-month FY doctor rotation period from April to the end of July 2013. The study was undertaken in four inpatient wards with a total of 59 beds in a tertiary centre renal unit at a UK teaching hospital in the East Midlands. All patients were admitted under specialist renal care.

\section{Data collection and analyses}

A paper-based data collection form adopted from Dornan $e t a l^{13}$ was designed and piloted for 7 days to ensure the team of six renal clinical pharmacists could reliably and practically use it for identifying and coding medication errors. Prior to the study, the clinical pharmacists received training on capturing data and categorising error severity. Medicine prescribing errors were recorded during the usual review of medical charts undertaken by ward-based pharmacists to minimise disruption to clinical service. All prescribing errors were recorded alongside the demographic details of the patient, prescriber details and location when making the prescription, and details of the medicine prescribed. All prescribing errors detected were corrected as part of the pharmacists' clinical role in the unit. In order to determine the number of errors as a proportion of the number of total prescriptions, the total number of medicine prescribed over the 4-month period was recorded daily from Monday to Friday. All error forms were peer reviewed by one of the senior renal pharmacists to ensure the accuracy of data. Another senior renal clinical pharmacist peer reviewed the completed forms, and gained consensus from the wider team about the potential for patient harm if the error was undetected. The renal function of patients in whom errors were detected was calculated using the Cockroft-Gault equation and the appropriate medication resource consulted to determine the correct dosing (Renal Drug Handbook, ${ }^{16}$ electronic Medicines Compendium, ${ }^{17}$ Micromedex and local guidelines). Data were anonymised prior to entry into a spreadsheet for analyses. A limitation of data collection from handwritten charts meant that it was not feasible to collect prescriber information for every prescription made, and so the total number of prescriptions made per prescriber was not captured in this study.

All errors were grouped according to the medicine name and error type for both FY doctors and all other prescribers. All errors were further categorised using the EQUIP criteria. ${ }^{13}$ All serious or lethal errors (those involving erythropoiesisstimulating agents, antibiotics and phosphate binders) were reported in more depth. The prescribing errors were categorised into 37 error types. ${ }^{13}$

The study was completed as part of the University Hospitals of Leicester NHS Trust's commitment to ensuring patient safety and improving quality. The study was registered with the clinical effectiveness team in the trust, reference number 6608E. Therefore, all issues related to perceptions of surveillance and temporary behaviour changes were minimised.

The results are compared between FY doctors and all other prescribers (senior trainees, nurses, a dietician, consultants and core trainees) under six headings: total number of errors, medicines associated with errors, type of error, type of renal-specific error, severity of error, medicines specific to kidney disease, and antibiotics.

The most junior members of the medical team only complete prescriptions using a computer at patient discharge and so any errors had a potentially different aetiology from those associated with handwritten charts. Discharge data were therefore excluded from analyses.

\section{RESULTS}

\section{Total number of errors}

A total of 10394 prescribed items were captured during the 4-month study. The pharmacy team identified 368 (3.54\%) as having prescribing errors. Some errors were removed from the analyses due to missing information, as follows:

- $56(15.2 \%)$ errors were not attributable to any prescriber due to signatures being omitted, unknown or unreadable.

- $13(3.5 \%)$ errors were attributable to FY doctors not routinely based on the renal unit. These prescriptions were likely written by doctors during on-call shifts, or when patients were elsewhere.

The FY doctors $(\mathrm{n}=14)$ made $169(56.52 \%)$ prescribing errors, while all other prescribers $(n=33)$ made 130 (table 1 ). Therefore, Foundation Year 1 (FY1) doctors individually made almost four times as many prescribing errors as all other prescribers and twice as many as Foundation Year 2 (FY2) doctors, while FY2 doctors made twice as many prescribing errors as all other prescribers. 
Table 1 Prescribing error frequency by occupational group

\begin{tabular}{llll}
\hline & \multicolumn{2}{l}{ Prescriber occupational grade } & \\
\cline { 2 - 3 } & $\begin{array}{l}\text { Foundation } \\
\text { Year 1 }\end{array}$ & $\begin{array}{l}\text { Foundation } \\
\text { Year 2 }\end{array}$ & $\begin{array}{l}\text { All other } \\
\text { prescribers }\end{array}$ \\
\hline Prescribers $(\mathrm{n})$ & 8 & 6 & 33 \\
Errors & $121(40.47 \%)$ & $48(16.05 \%)$ & $130(43.48 \%)$ \\
$\begin{array}{l}\text { Mean number of errors } \\
\text { per prescriber }\end{array}$ & 15.13 & 8.00 & 3.94 \\
\hline
\end{tabular}

\section{Medicines associated with prescribing errors}

The 299 prescription errors concerned 115 different medicines. Table 2 lists the most common medicines involved in prescribing errors by order of prevalence. The most common medicines for the FY doctors were paracetamol and calcium acetate, while for all other prescribers they were meropenem, alfacalcidol, co-amoxiclav and tacrolimus. More than half of the medicines $(n=65)$ were associated with only one error.

\section{Type of error}

An additional 37 errors were included for a total of 336 errors as 32 errors had two error types and five had three error types. Table 3 shows the 10 most common error types by order of prevalence, with an example for each. The top three error types were the same for the FY doctors and all other prescribers, and were 'omission-indication', 'brand name' and 'wrong dose'.

\section{Renal specific errors}

Examples of prescribing errors specific to kidney disease are provided in table 4 .

\section{Potential severity of error}

The potential severity of error was similar between the FY and other prescriber groups (table 5), with a similar percentage of minor and significant errors and fewer serious errors. One lethal error, attributed to a FY2 doctor, concerned the immunosuppressant medicine tacrolimus with $500 \mathrm{mg}$ prescribed rather than 500 micrograms.

\section{Medicines specific to kidney disease}

Erythropoiesis-stimulating agents were associated with $5.02 \%$ of errors $(n=15)$. The medicines involved were darbepoetin alfa (FY, $n=4$; others, $n=5$ ), epoetin alfa (FY, $n=3$; others, $n=2$ ) and erythropoietin ( $\mathrm{FY}, \mathrm{n}=1)$.

Phosphate binders were involved in almost 9\% of errors $(n=24)$ (table 6). Calcium acetate was the most common bone biochemistry medicine associated with prescribing errors. Nine phosphate binders prescribing errors were classified as minor (36\%), 14 as significant (60\%) and one as serious (4\%).

\section{Antibiotics}

Almost $20 \%$ of errors $(n=58)$ concerned antibiotics (table 7 ), with meropenem and tazocin involved in almost $25 \%$ of these, followed by doxycycline and co-amoxiclav (19\%). These percentages were relatively consistent for FY doctors and all other prescribers.

\section{DISCUSSION}

This is the first study to explore the prescribing behaviour of healthcare professionals, in particular FY doctors, working in a renal unit in the UK. The study found that over the 4-month observation period, FY1 doctors made four times and FY2 doctors twice as many errors as other healthcare professionals. This supports prior research reporting that FY doctors make more errors individually than other prescribers. ${ }^{12} 13$ It is not possible to quantify the extent of this problem without knowing the proportion of prescriptions written by both groups. Nonetheless, the findings suggest that FY doctors would benefit from educational interventions tailored to their specific learning needs. $^{15}$

Paracetamol was the medicine most frequently associated with a prescribing error, with FY doctors making proportionally twice as many errors as other healthcare professionals. Paracetamol was previously found to be one of the five most common incorrectly prescribed medicines in UK critical care units, ${ }^{21}$ with FY doctors proportionally making far more errors

Table 2 Medicines most commonly involved in a prescribing error by rank for group, number of observed prescribing errors and percentage within prescribing group

\begin{tabular}{|c|c|c|c|c|c|c|c|c|c|}
\hline & \multicolumn{3}{|l|}{ Total } & \multicolumn{3}{|c|}{ Foundation Year 1 and 2} & \multicolumn{3}{|c|}{ All other prescribers } \\
\hline & Rank & Observed & Percentage & Rank & Observed & Percentage & Rank & Observed & Percentage \\
\hline Paracetamol & 1 & 15 & $5.02 \%$ & 1 & 11 & $6.51 \%$ & 9 & 4 & $3.08 \%$ \\
\hline Calcium acetate & 2 & 14 & $4.68 \%$ & 2 & 9 & $5.33 \%$ & 4 & 5 & $3.85 \%$ \\
\hline Meropenem & 2 & 14 & $4.68 \%$ & 3 & 6 & $3.55 \%$ & 1 & 8 & $6.15 \%$ \\
\hline Alfacalcidol & 4 & 12 & $4.01 \%$ & 3 & 6 & $3.55 \%$ & 2 & 6 & $4.62 \%$ \\
\hline Tazocin & 5 & 11 & $3.68 \%$ & 3 & 6 & $3.55 \%$ & 4 & 5 & $3.85 \%$ \\
\hline Co-amoxiclav & 5 & 11 & $3.68 \%$ & 6 & 5 & $2.96 \%$ & 2 & 6 & $4.62 \%$ \\
\hline Tacrolimus & 7 & 10 & $3.34 \%$ & 9 & 4 & $2.37 \%$ & 2 & 6 & $4.62 \%$ \\
\hline Darbepoetin alfa & 8 & 9 & $3.01 \%$ & 9 & 4 & $2.37 \%$ & 4 & 5 & $3.85 \%$ \\
\hline Dalteparin & 9 & 8 & $2.68 \%$ & 15 & 3 & $1.78 \%$ & 4 & 5 & $3.85 \%$ \\
\hline Insulin & 10 & 7 & $2.34 \%$ & 6 & 5 & $2.96 \%$ & 15 & 2 & $1.54 \%$ \\
\hline Flucloxacillin & 10 & 7 & $2.34 \%$ & 15 & 3 & $1.78 \%$ & 9 & 4 & $3.08 \%$ \\
\hline Sando-K & 13 & 6 & $2.01 \%$ & 9 & 4 & $2.37 \%$ & 15 & 2 & $1.54 \%$ \\
\hline Zopiclone & 12 & 6 & $2.01 \%$ & 9 & 4 & $2.37 \%$ & 15 & 2 & $1.54 \%$ \\
\hline Sevelamer & 14 & 5 & $1.67 \%$ & 6 & 5 & $2.96 \%$ & 0 & 0 & $0.00 \%$ \\
\hline Epoetin alfa & 14 & 5 & $1.67 \%$ & 15 & 3 & $1.78 \%$ & 15 & 2 & $1.54 \%$ \\
\hline Metronidazole & 14 & 5 & $1.67 \%$ & 32 & 1 & $0.59 \%$ & 9 & 4 & $3.08 \%$ \\
\hline Novomix 30 & 14 & 5 & $1.67 \%$ & 32 & 1 & $0.59 \%$ & 9 & 4 & $3.08 \%$ \\
\hline
\end{tabular}




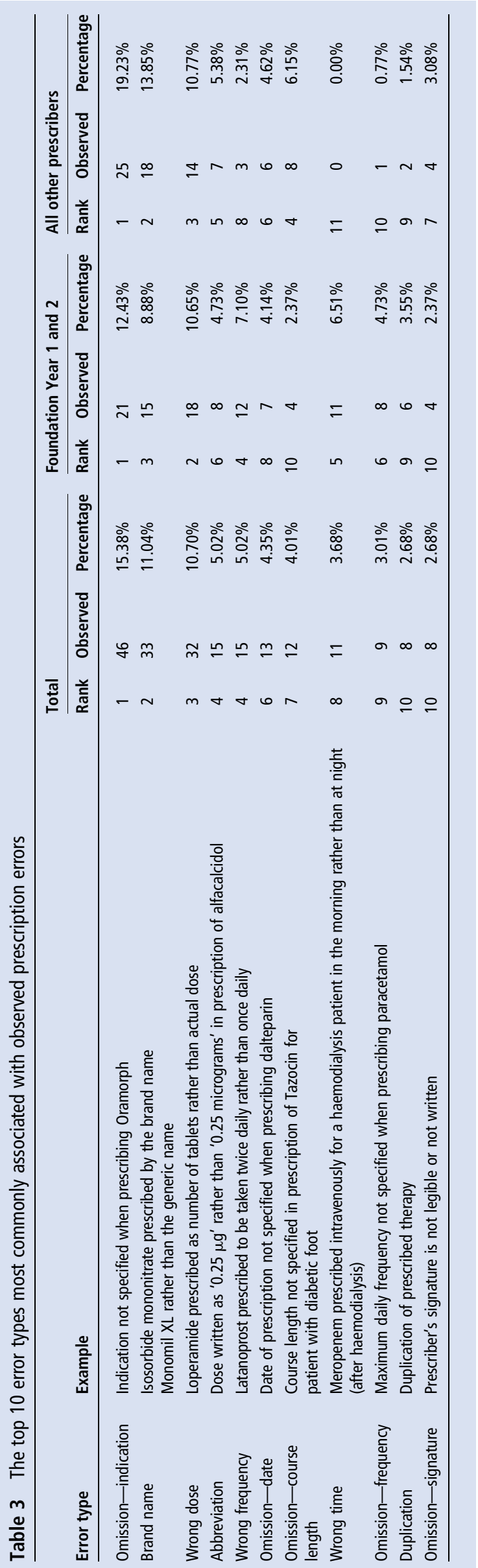

related to paracetamol than other healthcare professionals. While paracetamol is freely available over the counter and is often considered to require no specific prescription knowledge, it must be used cautiously in certain patient groups and dose adjusted in patients with lower weight. While only $10 \%$ of errors in this study were related to dosing, percentages of up to $43 \%$ were previously reported. ${ }^{8}$ Dornan et al found FY doctors did not mention safety when discussing their errors, ${ }^{13}$ and so the lack of safe prescribing behaviours may help explain the observed error rate identified in this study.

Medicines usually associated with kidney disease (erythropoiesis-stimulating agents, phosphate binders and immunosuppressive drugs) were involved in a third of all prescribing errors. This suggests two things. First, prescribing in patients with renal disease is challenging due to the complexity involved $^{1-7}$ irrespective of the clinical experience of the prescriber. Second, patients with renal disease experience prescribing errors for reasons likely unrelated to the complexity of their condition or a prescriber's lack of knowledge of renal medicine. Possible explanations for errors made by prescribers may relate to human factors, for example, "slips in attention, memory lapses, the effects of workload and environment, interruptions, hierarchies and poor communication" (ref. 23, p. 455). Further research is required to establish the relevant individual, social, contextual and environmental factors and what educational and organisational interventions can be developed to overcome them.

The error types identified in this study confirm that FY doctors and other prescribers are equally prone to making errors related to omission, wrong dosage and using brand names for medicines. This seems to be a generic problem across all prescribers irrespective of clinical context as confirmed by Taylor $e a^{24}$ who reported similar outcomes after investigating errors on handwritten prescription charts in a paediatric emergency department. Comparisons of error type are difficult since coding classification is heterogeneous and there is little standardisation of coding or definitions across studies.

Using the brand name when prescribing medicines is an error in some prescribing contexts. However, in other contexts not prescribing using brand names can cause significant patient safety issues. ${ }^{25}$ For example, prescribing using the brand name is a policy requirement for specific transplantation medicines, such as tacrolimus. In this case, an inadvertent brand switch could cause clinically significant negative outcomes such as transplant rejection or drug toxicity. These conflicting guidelines-requiring a brand name in some cases but discouraging it in otherscan be a potential source of error for novice prescribers.

Although there may be an issue with associating the use of brand names with prescribing errors, references such as the Renal Drug Handbook and the electronic Medicines Compendium include clear information and guidance on medication dosing in renal medicine. Although these resources were available in the renal unit, wrong dosage was a frequent and consistent problem irrespective of the type of prescriber. This suggests that the problem is related to human factors issues which should be identified by further research on systemic factors surrounding prescribing.

This study found the majority of prescribing errors had the potential for minor or significant harm, consistent with prior studies. ${ }^{13} 21$ As a proportion of all prescriptions, fewer errors were found $(3.54 \%)$ in this study compared with more general prescribing contexts. For example, Ridley et $a l^{21}$ reported an error rate of $14.55 \%$ over a 4 -week period in 24 critical care units, and Dornan et $\mathrm{al}^{13}$ reported an error rate of $8.91 \%$ over 
Table 4 Error type for renal-specific errors, categorised by type of medication, error description, potential negative outcome and severity

\begin{tabular}{|c|c|c|c|}
\hline Medication category & Error description & Potential negative outcome & Severity \\
\hline \multirow[t]{2}{*}{$\begin{array}{l}\text { Medicines used in chronic } \\
\text { kidney disease }\end{array}$} & $\begin{array}{l}\text { Prescription for 'Epo'. Inappropriate abbreviation used with no } \\
\text { brand or dose specified }\end{array}$ & $\begin{array}{l}\text { Prescription is unclear and therefore nursing staff would be } \\
\text { unable to administer the medication. As a consequence, the } \\
\text { patient may not receive the treatment or it could lead to } \\
\text { inappropriate delays. }\end{array}$ & Severe \\
\hline & $\begin{array}{l}\text { Calcium carbonate prescribed as a phosphate binder for a } \\
\text { patient with hypercalcaemia }\end{array}$ & $\begin{array}{l}\text { Exacerbation of hypercalcaemia potentially causing lethargy, } \\
\text { weakness, confusion, coma, constipation, nausea, anorexia and } \\
\text { arrhythmias }\end{array}$ & Severe \\
\hline Anticoagulation & $\begin{array}{l}\text { Dalteparin (12 } 500 \text { units once daily) prescribed for a deep } \\
\text { venous thrombosis in a patient on haemodialysis }\end{array}$ & $\begin{array}{l}\text { Low molecular weigh heparins given at conventional treatment } \\
\text { doses to patients on haemodialysis will accumulate, which can } \\
\text { complicate reversal of anticoagulation. }\end{array}$ & Severe \\
\hline \multirow[t]{4}{*}{ Antimicrobials } & $\begin{array}{l}\text { Clarithromycin prescribed in combination with tacrolimus and } \\
\text { atorvastatin (significant interactions) }\end{array}$ & $\begin{array}{l}\text { Increased exposure to atorvastatin and tacrolimus, which could } \\
\text { lead to myopathy (atorvastatin) and nephrotoxicity and } \\
\text { neurotoxicity (tacrolimus) }\end{array}$ & Severe \\
\hline & $\begin{array}{l}\text { Wrong dose of ganciclovir prescribed ( } 500 \mathrm{mg} \text { tds instead of } \\
500 \mathrm{mg} \mathrm{bd} \text { ) }\end{array}$ & $\begin{array}{l}\text { Increased exposure to ganciclovir, which could lead to } \\
\text { neurotoxicity and myelosuppression }\end{array}$ & Severe \\
\hline & $\begin{array}{l}\text { Incorrect (too high) dose of meropenem prescribed for a } \\
\text { patient receiving haemodialysis }\end{array}$ & $\begin{array}{l}\text { Increased exposure to meropenem which could lead to } \\
\text { neurotoxicity }\end{array}$ & Severe \\
\hline & $\begin{array}{l}\text { Valganciclovir unintentionally omitted from a renal transplant } \\
\text { patient medication card when it was required }\end{array}$ & $\begin{array}{l}\text { Omitting valganciclovir in these cases could result in increased } \\
\text { risk of cytomegalovirus disease }\end{array}$ & Severe \\
\hline \multirow[t]{3}{*}{ Immunosuppression } & $\begin{array}{l}\text { Treatment with mycophenolate mofetil inadvertently continued } \\
\text { for a renal transplant patient with cytomegalovirus infection }\end{array}$ & $\begin{array}{l}\text { If immunosuppression is not minimised, this could compromise } \\
\text { the success of treatment for cytomegalovirus disease in renal } \\
\text { transplant patients. }\end{array}$ & Severe \\
\hline & $\begin{array}{l}\text { New transplant patient whose medication chart did not include } \\
\text { any immunosuppression or adjuvant agents given after renal } \\
\text { transplantation. This patient was prescribed inappropriate } \\
\text { medicines such as high-dose furosemide and phosphate binders } \\
\text { (no longer indicated) }\end{array}$ & $\begin{array}{l}\text { Lack of prescribed immunosuppression following renal } \\
\text { transplantation will increase the risk of acute rejection and graft } \\
\text { loss. }\end{array}$ & Severe \\
\hline & Prograf dose prescribed as $500 \mathrm{mg}$ instead of 500 micrograms & $\begin{array}{l}\text { Although it is unlikely that the dose would have been given } \\
\text { (100 capsules of } 5 \mathrm{mg} \text { would have to be administered), this error } \\
\text { constitutes a } 1000 \text {-fold overdose which would almost certainly } \\
\text { be fatal. }\end{array}$ & Lethal \\
\hline
\end{tabular}

seven 'census days' in a study of 19 acute hospital trusts. The wide range in error rate observed in these studies should be the subject of further research. The variation may reflect differences in prescribing contexts across situations, such as level of prescribing support for healthcare professionals, prescribing experience, and familiarity with the patient population by the prescriber.

While the clinical supervision of FY doctors by senior medical doctors is well established, the educational input by pharmacists remains underutilised in terms of formal teaching and learning. The type of renal-specific errors suggests contextspecific knowledge is crucial to reduce severe and lethal errors. Pharmacist-led interventions help reduce prescribing errors among FY doctors and could do so in specialist contexts. ${ }^{26}$ Furthermore, clinical pharmacists already contribute to undergraduate education, ${ }^{27}$ so extending their role across the continuum of medical education may be a cost-effective strategy for reducing avoidable harm in complex clinical settings such as the renal unit. Further research is necessary to establish the feasibility of using pharmacists for delivering medical education, given the significant pressures clinical pharmacy services face. Nevertheless, in light of the consistency of findings suggesting FY doctors are error prone, the risk to patient safety from prescribing errors in complex settings may warrant additional resources.

There are two main limitations to this research. First, subgroup analysis between professional groups was not possible as the total number of prescriptions made by each prescribing group was not known. While prescription errors by individual medicine name were known for each prescriber, the total number of prescriptions for each medicine was unknown, so calculating relative risk by medicine name was not possible. Without this information, this study was unable to establish whether the error rate of FY doctors in relation to the proportion of prescriptions is higher than for other prescribers, or to ascertain which medicine is associated with the highest rate of prescribing errors.

Table 5 Prescription errors by potential severity of error

\begin{tabular}{|c|c|c|c|c|c|c|c|}
\hline \multirow{2}{*}{$\begin{array}{l}\text { Potential severity of error } \\
\text { Minor }\end{array}$} & \multirow{2}{*}{$\begin{array}{l}\text { Example } \\
\text { Simvastatin prescribed in the morning rather than at night }\end{array}$} & \multicolumn{2}{|c|}{ Total } & \multicolumn{2}{|c|}{$\begin{array}{l}\text { Foundation } \\
\text { Year } 1 \text { and } 2\end{array}$} & \multicolumn{2}{|c|}{$\begin{array}{l}\text { All other } \\
\text { prescribers }\end{array}$} \\
\hline & & 129 & $43.14 \%$ & 66 & $39.05 \%$ & 63 & $48.46 \%$ \\
\hline Significant & No maximum frequency stated when paracetamol prescribed & 124 & $41.47 \%$ & 73 & $43.20 \%$ & 51 & $39.23 \%$ \\
\hline Serious & Co-amoxiclav prescribed to patient with known penicillin allergy & 45 & $15.05 \%$ & 29 & $17.16 \%$ & 16 & $12.31 \%$ \\
\hline Lethal & $500 \mathrm{mg}$ of tacrolimus prescribed instead of 500 micrograms & 1 & $0.33 \%$ & 1 & $0.59 \%$ & 0 & $0.00 \%$ \\
\hline Total & & 299 & $100 \%$ & 169 & $100 \%$ & 130 & $100 \%$ \\
\hline
\end{tabular}


Table 6 Phosphate binders most commonly associated with prescribing errors

\begin{tabular}{|c|c|c|c|c|c|c|c|c|c|}
\hline \multirow[b]{2}{*}{ Phosphate binder } & \multicolumn{3}{|l|}{ Total } & \multicolumn{3}{|c|}{ Foundation Year 1 and 2} & \multicolumn{3}{|c|}{ All other } \\
\hline & Rank & Observed & Percentage & Rank & Observed & Percentage & Rank & Observed & Percentage \\
\hline Calcium acetate & 1 & 14 & $56.00 \%$ & 1 & 9 & $50.00 \%$ & 1 & 5 & $71.43 \%$ \\
\hline Sevelamer & 2 & 5 & $20.00 \%$ & 2 & 5 & $27.78 \%$ & 3 & 0 & $0.00 \%$ \\
\hline Lanthanum carbonate & 3 & 4 & $16.00 \%$ & 3 & 3 & $16.67 \%$ & 2 & 1 & $14.29 \%$ \\
\hline Adcal D3 & 4 & 1 & $4.00 \%$ & 4 & 1 & $5.56 \%$ & 3 & 0 & $0.00 \%$ \\
\hline Total & & 24 & $100 \%$ & & 18 & $100 \%$ & & 6 & $100 \%$ \\
\hline
\end{tabular}

Second, the design of the study was limited to a time period corresponding to a single rotation of doctors and a single centre where handwritten drug charts were used for prescribing medication. Hospitals are increasingly adopting computerised systems to support prescribing, which reduces the potential for adverse medicine events, ${ }^{28}$ particularly in outpatient settings for patients with CKD. However, these systems are not error free and have not always been subject to rigorous evaluation. ${ }^{29}$ Minor and significant errors can be eradicated with electronic prescribing, but timesaving workarounds could be used to continue to omit information, depending on how well the systems are designed. Renal-specific errors are unlikely to be eradicated and should be considered in the design of future computerised systems. Given that electronic prescribing is being more widely adopted, further research will be required into its effects on the types of medicines involved in prescribing errors, the type of prescribing errors when using these electronic prescribing systems, and the implications this has for the targeting of education and human factors interventions.

All final year medical students in the UK are now expected to successfully complete the Prescribing Skills Assessment in order to progress into the Foundation Programme. ${ }^{30}$ This assessment measures basic level competence upon entry into the workplace, but there are no further assessments thereafter. So the prescribing performance of FY doctors is generally not checked after medical school. Although formal assessments may be impractical in the postgraduate setting, workplace-based assessments around prescribing are established and could be used more extensively to ensure FY doctors have the knowledge, skills and attitudes required for safe prescribing.

The differences in prescribing errors between professional groups in this study suggest targeted practice-based education for FY doctors is necessary to improve prescribing performance, especially in complex settings like a renal unit. Furthermore, the educational role of clinical pharmacists should be developed given they have significant specialty-specific domain knowledge and currently have limited input into postgraduate medical education. Although the role of the pharmacist is well established in the context of medicines reconciliation, a larger multi-site and multi-context study is needed to evaluate the effectiveness of pharmacist-led education for FY doctors in complex clinical areas.

The high frequency of prescribing errors made by FY doctors compared with senior healthcare professionals is consistent with findings from previous studies. The proportion of errors per prescriber appears to reflect the clinical experience of the prescriber, suggesting educational interventions should focus on developing prescribing competence rather than increasing subject- or domain-specific knowledge. Any educational intervention must also consider human factors issues given that errors can be caused by situational and systematic factors. Although a third of prescribing errors were associated with medicines specifically prescribed for patients with kidney disease, two-thirds related to generic or commonly prescribed medicines such as paracetamol. These common errors were similar for FY doctors and for other prescribers, so the findings have implications for the development of renal-specific prescribing education as well as prescribing education in general. Nevertheless, FY doctors specifically make prescribing errors that are potentially significant for patients in a renal unit compared to other areas. Therefore, educational interventions should be implemented in practice-based settings where pharmacists are present and already play important roles in medicines safety on the ward. A standardised system for categorising prescribing errors must be adopted to enable comparisons across interventions.

Table 7 Antibiotic medicines most commonly associated with prescribing errors

\begin{tabular}{|c|c|c|c|c|c|c|c|c|c|}
\hline \multirow[b]{2}{*}{ Antibiotic medicine } & \multicolumn{3}{|l|}{ Total } & \multicolumn{3}{|c|}{ Foundation Year 1 and 2} & \multicolumn{3}{|c|}{ All other prescribers } \\
\hline & Rank & Observed & Percentage & Rank & Observed & Percentage & Rank & Observed & Percentage \\
\hline Meropenem & 1 & 14 & $24.14 \%$ & 1 & 6 & $20.69 \%$ & 1 & 8 & $27.59 \%$ \\
\hline Tazocin & 2 & 11 & $18.97 \%$ & 2 & 5 & $17.24 \%$ & 2 & 6 & $20.69 \%$ \\
\hline Co-amoxiclav & 2 & 11 & $18.97 \%$ & 2 & 5 & $17.24 \%$ & 2 & 6 & $20.69 \%$ \\
\hline Flucloxacillin & 4 & 7 & $12.07 \%$ & 4 & 3 & $10.34 \%$ & 4 & 4 & $13.79 \%$ \\
\hline Metronidazole & 5 & 5 & $8.62 \%$ & 8 & 1 & $3.45 \%$ & 4 & 4 & $13.79 \%$ \\
\hline Doxycycline & 6 & 4 & $6.90 \%$ & 4 & 3 & $10.34 \%$ & 6 & 1 & $3.45 \%$ \\
\hline Clarithromycin & 7 & 2 & $3.45 \%$ & 6 & 2 & $6.90 \%$ & 7 & 0 & $0.00 \%$ \\
\hline Pyrazinamide & 7 & 2 & $3.45 \%$ & 6 & 2 & $6.90 \%$ & 7 & 0 & $0.00 \%$ \\
\hline Rifampicin & 9 & 1 & $1.72 \%$ & 8 & 1 & $3.45 \%$ & 7 & 0 & $0.00 \%$ \\
\hline Rifinah & 9 & 1 & $1.72 \%$ & 8 & 1 & $3.45 \%$ & 7 & 0 & $0.00 \%$ \\
\hline Total & & 58 & $100 \%$ & & 29 & $100 \%$ & & 29 & $100 \%$ \\
\hline
\end{tabular}


Key messages

What is already known on this subject

- Prescribing errors, especially among Foundation Year doctors (doctors who are in their first 2 years of practice following graduation from medical school in the UK), are common and an avoidable cause of adverse harm involving medication.

- Prescribing medicines to patients with kidney disease is complex and challenging due to the high prevalence of multimorbidity and the greater risks associated with polypharmacy.

- There is little research exploring the type of prescribing errors in patients with kidney disease.

\section{What this study adds}

- Prescribing errors in a specialist renal unit were compared to findings from other studies and found to contain a higher proportion with the potential to cause severe consequences.

- The quantity of prescribing errors among Foundation Year doctors was associated with their years of clinical experience: Foundation Year 1 doctors made twice the number of errors as Foundation Year 2 doctors, and Foundation Year 2 doctors made twice the number of errors as other prescribers.

- Paracetamol was most frequently associated with prescribing errors made by Foundation Year doctors.

- Further research is required to develop appropriate interventions based on the findings of this study and identify educational solutions to the human factors elements in prescribing errors.

Acknowledgements The authors would like to thank Gill Hartley, Jo Hadley, Chetna Modi, Reena Valand and the junior pharmacists who assisted the study, as well as Professor Sue Carr and all the staff on the John Walls Renal Unit at Leicester General Hospital. We wish to thank the anonymous reviewers for their comments which have improved the paper.

Funding The National Institute of Health Research funded Dr Patel's Academic Clinical Lectureship (ACL) and associated research. This study was part-funded by Health Education East Midlands (study reference: LEI0085). Pfizer Pharmaceuticals through an unrestricted educational project grant also provided part funding for the lead pharmacist. Small financial and in kind contributions were also received from the University Hospitals of Leicester NHS Trust and the University of Leicester.

Competing interests None.

Provenance and peer review Not commissioned; externally peer reviewed. Data sharing statement Please contact the corresponding author if you wish obtain data.

Open Access This is an Open Access article distributed in accordance with the Creative Commons Attribution Non Commercial (CC BY-NC 4.0) license, which permits others to distribute, remix, adapt, build upon this work non-commercially, and license their derivative works on different terms, provided the original work is properly cited and the use is non-commercial. See: http://creativecommons.org/ licenses/by-nc/4.0/

\section{REFERENCES}

1 Lesar TS, Briceland L, Stein DS. Factors related to errors in medication prescribing. JAMA 1997;277:312-17.
2 Hug BL, Witkowski DJ, Sox CM, et al. Occurrence of adverse, often preventable, events in community hospitals involving nephrotoxic drugs or those excreted by the kidney. Kidney Int 2009;76:1192-8.

3 Coresh J, Selvin E, Stevens LA, et al. Prevalence of chronic kidney disease in the United States. JAMA 2007;298:2038-47.

4 Schafer I. Does multimorbidity influence the occurrence rates of chronic conditions? A claims data based comparison of expected and observed prevalence rates. PLoS ONE 2012:7:e45390.

5 Nobili A, Garattini S, Mannucci PM. Multiple diseases and polypharmacy in the elderly: challenges for the internist of the third millennium. J Comorbidity 2011;1:28-44.

6 McLean AJ, Le Couteur DG. Aging biology and geriatric clinical pharmacology. Pharmacol Rev 2004;56:163-84.

7 Olyaei AJ, Bennett WM. Drug dosing in the elderly patients with chronic kidney disease. Clin Geriatr Med 2009;25:459-527.

8 Cox ZL, McCoy AB, Matheny ME, et al. Adverse drug events during AKI and its recovery. Clin J Am Soc Nephrol 2013;8:1070-8.

9 Dean B, Barber N, Schachter M. What is a prescribing error? Qual Health Care 2000;9:232-7.

10 Lewis PJ, Dornan T, Taylor D, et al. Prevalence, incidence and nature of prescribing errors in hospital inpatients. Drug Saf 2009;32:379-89.

11 Franklin $B D$, Reynolds $M$, Shebl NA, et al. Prescribing errors in hospital inpatients: a three-centre study of their prevalence, types and causes. Postgrad Med J 2011;87:739-45.

12 Dean B, Schachter M, Vincent C, et al. Prescribing errors in hospital i npatients: their incidence and clinical significance. Qual Saf Health Care 2002:11:340-4.

13 Dornan T, Ashcroft D, Heathfield H, et al. An in-depth investigation into causes of prescribing errors by foundation trainees in relation to their medical education: EQUIP study. London: General Medical Council, 2009:1-215.

14 Baqir W, Crehan O, Murray R, et al. Pharmacist prescribing within a UK NHS hospital trust: nature and extent of prescribing, and prevalence of errors. Eur J Hosp Pharm 2014;22:79-82

15 Kamarudin G, Penm J, Chaar B, et al. Educational interventions to improve prescribing competency: a systematic review. BMJ Open 2013;3:e003291.

16 Ashley C, Dunleavy A. eds. The renal drug handbook. 4th edn. Oxford: Radcliffe Publishing, 2014.

17 Electronic medicines compendium (eMC) [Internet]. 2014. http://www.medicines.org uk/emcl

18 Jhaveri KD, Sparks MA, Shah HH, et al. Why not nephrology? A survey of US internal medicine subspecialty fellows. Am J Kidney Dis 2013;61:540-6.

19 Ross S, Loke YK. Do educational interventions improve prescribing by medical students and junior doctors? A systematic review. Br I Clin Pharmacol 2009;67:662-70.

20 Ryan C, Ross S, Davey P, et al. Prevalence and causes of prescribing errors: the PRescribing Outcomes for Trainee doctors Engaged in Clinical Training (PROTECT) study. PloS ONE 2014;9:e79802.

21 Ridley S, Booth S, Thompson C. Prescription errors in UK critical care units. Anaesthesia 2004:59:1193-200.

22 Vessal G. Detection of prescription errors by a unit-based clinical pharmacist in a nephrology ward. Pharm World Sci 2010;32:59-65.

23 Robson W. Prescribing errors: taking the human factor into account. Nurse Prescribing 2013;11:455-8.

24 Taylor BL, Selbst SM, Shah AE. Prescription writing errors in the pediatric emergency department. Pediatr Emerg Care 2005;21:822-7.

25 Kenagy JW, Stein GC. Naming, labeling, and packaging of pharmaceuticals. Am J Health Syst Pharm 2001;58:2033-41.

26 Webbe D, Dhillon S, Roberts CM. Improving junior doctor prescribing: the positive impact of a pharmacist intervention. Pharm I 2007;278:136-9.

27 Tittle V, Randall D, Maheswaran V, et al. Practical prescribing course: a student evaluation. Clin Teach 2014;11:38-42.

28 Ammenwerth E, Schnell-Inderst P, Machan C, et al. The effect of electronic prescribing on medication errors and adverse drug events: a systematic review. J Am Med Inform Assoc 2008; 15:585-600.

29 Nuckols TK, Smith-Spangler C, Morton SC, et al. The effectiveness of computerized order entry at reducing preventable adverse drug events and medication errors in hospital settings: a systematic review and meta-analysis. Syst Rev 2014;3:56

30 Catling F, Williams J, Baker R. A prescribing e-tutorial for medical students. Clin Teach 2014;11:33-7. 